\title{
Preface to The Mangled Modifier
}

\author{
Sean Kullman
}

"English usage is sometimes more than taste .... Sometimes, it's sheer luck, like getting across the street" (E.B. White). Toxicologists save lives and editors save the writing of toxicologists. In an attempt to promote good scientific writing, the editors of the Journal of Medical Toxicology will present common writing errors and solutions to the errors. So, pull-up a pen and read along.

\section{THE MANGLED MODIFIER}

A mangled modifier is a word or phrase that creates havoc with a sentence. How? It usurps an unsuspecting word or phrase. It sits in somebody else's seat. Many types of mangled modifiers exist. In the examples below, dangling (misplaced) participle phrases are the main culprit.

Incorrect: After leaving the ball, the limo picked up Cinderella. (Wait! The limo did not leave the ball; Cinderella left the ball).

Correct: After leaving the ball, Cinderella gently stepped into a pumpkin-colored limo.

(Participle phrase)

(Main clause)

Incorrect: Thirty minutes after receiving morphine, the pain in the patient was lessened. (The pain did not receive the morphine; the patient received the morphine).

Correct: The pain subsided in the patient thirty minutes after receiving morphine.

Dangling (misplaced) participle phrases create problems for the reader. The unsuspecting reader, lost in a page of uncertainty, remains disoriented and misplaced. Hoping to understand the sentence, the reader must seek out the modified word or phrase: be a prince, slip your modifier where it belongs.

\section{TIPS FOR NEXT ISSUE: 1) TO BE OR NOT TO BE}

